\title{
Intoxicação por enrofloxacina em um cão da raça Pinscher Miniatura: relato de caso
}

[Enrofloxacin poisoning in a Miniature Pinscher: a case report]

\author{
H.H.A. Barcellos ${ }^{1}$, S.T. Oliveira ${ }^{1}$, L.P. Alves ${ }^{1}$, A.C. Motta ${ }^{1}$, F.R. Rocha ${ }^{2}$, M.V. Brun ${ }^{1}$ \\ ${ }^{1}$ Faculdade de Agronomia e Medicina Veterinária - UPF \\ Caixa Postal 631 \\ 99001-970 - Passo Fundo, RS \\ ${ }^{2}$ Aluna de graduação - FAMV - UPF
}

\begin{abstract}
RESUMO
Uma cadela da raça Pinscher Miniatura foi medicada pelo proprietário com enrofloxacina, na dose de $50 \mathrm{mg} / \mathrm{kg}$, uma vez ao dia, por dois dias (dose diária 10 vezes maior que a prescrita). Ao exame clínico o animal apresentou-se deprimido, em cifose lombar, hipotérmico, com mucosas pálidas, dispnéia, sialorréia, vômitos e anúria, evoluindo para parada respiratória, convulsões e coma. Foi realizado tratamento sintomático. O fluxo urinário retornou ao normal em 12 horas e as convulsões foram controladas, mas o animal permaneceu em coma, morrendo 72 horas após o início do tratamento. A necropsia e o histopatológico confirmaram insuficiência renal e hepática agudas, e choque hipovolêmico, compatível com intoxicação por enrofloxacina.
\end{abstract}

Palavras-chave: cão, fluorquinolona, intoxicação, choque, enrofloxacina

\begin{abstract}
A Miniature Pinscher bitch was treated by the owner with enrofloxacin at dose of $50 \mathrm{mg} / \mathrm{kg}$, once a day, for two days (daily dose rate 10 times greater than prescribed). Physical examination showed depression, lumbar cifosis, hipotermia, pale mucosa, dispneia, drewling, vomiting and anuria, followed by respiratory failure, seizures, and coma. Symptomatic treatment was performed, and the urinary flow returned to normal in 12 hours, and seizures were controlled. However, the animal stayed in coma, and died 72 hours after the beginning of the treatment. Acute renal and hepatic failure, and hipovolemic shock, compatible with enrofloxacin intoxication, were observed through necropsia and histopatology.
\end{abstract}

Keywords: canine, fluoroquinolone, overdose, shock, enrofloxacin

\section{INTRODUÇ̃̃O}

A enrofloxacina foi a primeira fluorquinolona introduzida na medicina veterinária. Todas as fluorquinolonas são bactericidas e atuam inibindo a DNA-girase bacteriana (topoisomerase tipo II) (Vancutsem et al., 1990; Sárközy, 2001). Este antimicrobiano tem amplo espectro de atividade, sendo eficaz contra bactérias gram-negativas e algumas gram- positivas, contra Mycoplasma e Chlamydia.

Bactericida em concentrações relativamente baixas, utilizada por administração oral ou parenteral, na maioria das espécies alcança boa penetração nos tecidos corporais e fluidos (Plumb, 1999; USP..., 2003; Sárközy, 2001). A eficácia clínica em cães foi estabelecida especificamente no tratamento de infecções de pele e de tecidos moles, nas infecções do trato respiratório e cistite bacteriana (USP..., 2003).

Recebido 22 de agosto de 2005

Aceito em 5 de dezembro de 2005

E-mail: heloisa@upf.br 
A dose diária recomendada para cães é de $5 \mathrm{mg} / \mathrm{kg}$, em uma ou duas administrações, o que resulta em nível plasmático de $1,66 \mu \mathrm{g} / \mathrm{ml}$. O tempo médio recomendado de administração é de cinco dias, mas o tratamento pode se estender até 10 dias, nos casos de infecções crônicas ou recorrentes (Vancutsem et al., 1990).

Parte da atividade antimicrobiana da enrofloxacina é atribuída ao seu metabólito principal, a ciprofloxacina. A concentração plasmática ativa é alcançada após a administração de $5 \mathrm{mg} / \mathrm{kg}$ de enrofloxacina em cães. A concentração inibitória mínima (CIM) de ciprofloxacina para vários microrganismos é mais baixa do que a CIM de enrofloxacina (Küng et al., 1993; Plumb, 1999; USP..., 2003; Otero et al., 2001). Cerca de $40 \%$ da enrofloxacina administrada por via endovenosa ou oral é convertida em ciprofloxacina, sendo distribuída para agir principalmente nos rins, fígado, pulmões, estômago, pele e sistema nervoso central (USP..., 2003).

Os efeitos colaterais da enrofloxacina em cães, de incidência rara, incluem vômito em $0,7 \%$ dos animais em dosagem oral de $5 \mathrm{mg} / \mathrm{kg} / \mathrm{dia}$ (USP..., 2003). Plumb (1999) citou ser improvável que a intoxicação aguda pela enrofloxacina possa resultar em sintomas mais graves do que anorexia e vômito.

O objetivo deste trabalho foi relatar a intoxicação de um cão por dosagem excessiva de enrofloxacina, levando a alterações gastrintestinais, urinárias, hepáticas, pulmonares e nervosas.

\section{CASUÍSTICA}

Uma cadela da raça Pinscher Miniatura, de um ano e sete meses, pesando $2,5 \mathrm{~kg}$, foi atendida em hospital veterinário. Ao exame clínico inicial, apresentou soluções de continuidade e edema na pele e tecido subcutâneo, localizadas na cabeça e laterais da região torácica, produzidas por mordedura de um cão de porte grande.
Foi realizada tricotomia e antissepsia com polivinil-pirrolidona-iodo $0,1 \%{ }^{1}$ nas feridas, três vezes ao dia. Foi admiistrado cetoprofeno ${ }^{2}$ como analgésico e antiinflamatório na dose de $2 \mathrm{mg} / \mathrm{kg}$ $(0,5 \mathrm{ml})$, a cada 24 horas, via subcutânea, por dois dias consecutivos, em face da reação inflamatória nos locais dos ferimentos, além de enrofloxacina $^{3}$, na dose de $5 \mathrm{mg} / \mathrm{kg}(0,5 \mathrm{ml})$, via subcutânea, a cada 24 horas, por quatro dias consecutivos, como terapia antimicrobiana. A paciente ficou internada durante dois dias, após o que recebeu alta. Em casa o tratamento foi mantido com enrofloxacina injetável e limpeza das feridas com polivinil-pirrolidona-iodo $0,1 \%{ }^{1}$.

Dois dias após a alta, o proprietário retornou ao hospital relatando que o animal, três horas depois da administração de enrofloxacina, apresentava vômitos intensos, de cor amarela e episódios de convulsão. Segundo o mesmo, o animal estava com oligúria e urina de cor alaranjada. Durante a anamnese sobre a forma de realização do tratamento do animal, foi constatado erro do proprietário na dosagem de enrofloxacina administrada: ao invés de administrar $0,5 \mathrm{ml}$ do medicamento (equivalente a $5 \mathrm{mg} / \mathrm{kg}$ ), o cliente aplicou $5 \mathrm{ml}$ (equivalente a $50 \mathrm{mg} / \mathrm{kg}$, ou seja, 10 vezes a dose indicada) por dia.

Ao exame clínico, o animal apresentava-se deprimido, em postura de cifose lombar, temperatura retal de $36^{\circ} \mathrm{C}$, hidratação normal, mucosas pálidas e sialorréia. $\mathrm{O}$ tempo de preenchimento capilar era de quatro segundos.

No exame neurológico ocular, não foram observadas alterações. À palpação abdominal, foi constatada sensibilidade dolorosa gástrica severa, intestinal moderada e renal acentuada. $\mathrm{Na}$ ausculta torácica, observaram-se dispnéia moderada, freqüência respiratória de 16 ciclos/minuto, arritmia cardíaca e freqüência cardíaca de 82 batimentos/minuto.

Após o exame clínico, a cadela apresentou convulsão, seguida de parada respiratória, sendo

\footnotetext{
${ }^{1}$ Riodeine tópico - Indústria Farmacêutica Rioquímica Ltda. - São José do Rio Preto - Brasil

${ }^{2}$ Ketofen $1 \%$ - Merial Saúde Animal Ltda.- São Paulo Brasil.

${ }^{3}$ Flotril 2,5\% - Schering -Plough Veterinária - Rio de
} Janeiro - Brasil. 
medicado com doxapram ${ }^{4}$, na dose de $2 \mathrm{mg} / \mathrm{kg}$, via intracardíaca. Em seguida, foi intubado com tubo traqueal de borracha número 3,5 e ventilado inicialmente com equipamento tipo ambu, seguida de oxigenioterapia e ventilação manual. $\mathrm{O}$ fluxo de oxigênio fornecido foi de um litro/minuto. Após uma hora de oxigenioterapia e ventilação manual, o animal voltou a respirar espontaneamente, porém, em alguns minutos, voltou a apresentar convulsão. A dispnéia acentuada provocou cianose, sendo mantida oxigenioterapia com máscara, com fluxo de 0,8 litros/minuto, durante 72 horas.

A paciente foi colocada em venóclise com solução glicofisiológica ${ }^{5}$, na velocidade de $10 \mathrm{ml} / \mathrm{kg} /$ hora e medicada com diazepam ${ }^{6}$, na dose de $2,8 \mathrm{mg} / \mathrm{kg}$, via intravenosa, para inibir a convulsão. Metoclopramida ${ }^{7}$ na dose de $0,5 \mathrm{mg} / \mathrm{kg}$, via intravenosa e cimetidina ${ }^{8}$ na dose de $6 \mathrm{mg} / \mathrm{kg}$, via subcutânea, ambas a cada seis horas, foram utilizadas no tratamento da gastrite instalada.

Durante as horas seguintes, foi avaliado o volume urinário produzido, através de cateterização uretral em sistema fechado de coleta de urina. Como o animal estava em anúria, apresentou edema pulmonar por excesso de fluido e foi medicado com furosemida ${ }^{9}$, na dose de $2 \mathrm{mg} / \mathrm{kg}$, via endovenosa. Após 15 minutos, continuava em anúria, sendo repetida a medicação na mesma dosagem. O animal apresentou o fluxo urinário de $0,25 \mathrm{ml} /$ minuto nas primeiras duas horas, após esta medicação. Nas 72 horas seguintes, urinou $0,67 \mathrm{ml} /$ minuto. A administração de furosemida foi mantida a cada seis horas, na dose de $4 \mathrm{mg} / \mathrm{kg}$, via intravenosa. Como exames complementares, foram mensuradas a alanina aminotransferase (ALT) e a fosfatase alcalina (ambas pelo método cinéticoenzimático ${ }^{10}$ ), creatinina sérica (pelo método do picrato alcalino ${ }^{10}$ ), hemograma (por contador hematológico de células, para a série vermelha ${ }^{11}$

\footnotetext{
${ }^{4}$ Viviram - Holliday-Scott S.A. - Buenos Aires - Argentina.

${ }^{5}$ Solução Glicofísiológica - Indústria Farmacêutica BASA

LTDA. - Caxias do sul - Brasil

${ }^{6}$ Compaz - Cristália Produtos Químicos e Farmacêuticos Ltda - Itapira - Brasil

${ }^{7}$ Metoclopramida - Ariston - São Paulo - Brasil.

${ }^{8}$ Cinton - Ariston - São Paulo - Brasil.

${ }^{9}$ Furosemida - Teuto Brasileiro - Anápolis - Brasil.

${ }^{10}$ Labtest - Labtest Diangóstica S.A. - Lagoa Santa - Brasil.

${ }^{11}$ MS4 Mellet - Mellet Schloesing Laboratories da América do Sul - Rio de Janeiro - Brasil
}

e contagem diferencial manual para a série branca) e urinálise (pelo método de tiras reagentes $^{12}$ e análise microscópica do sedimento). Todos estes exames foram realizados 24 horas após o início do tratamento.

A análise do hemograma (Tab. 1) evidenciou anemia macrocítica hipocrômica. A uréia e a ALT séricas (Tab. 2) estavam aumentadas e a creatinina em valor normal. A urinálise (Tab. 3) revelou $\mathrm{pH}$ urinário ácido, densidade baixa, presença de sangue e células epiteliais, cilindros e cristais de oxalato de cálcio.

Tabela 1. Hemograma da cadela Pinscher intoxicada por enrofloxacina, após 24 horas de tratamento

\begin{tabular}{lc}
\hline Variável & Valor \\
\hline Eritrócitos & $3,1 \times 10^{6} / \mathrm{mm}^{3}$ \\
Hematócrito & $30,3 \%$ \\
VCM & $98,0 \mathrm{fl}$ \\
CHCM & $38,6 \mathrm{~g} / \mathrm{dl}$ \\
Hemoglobina & $11,7 \mathrm{~g} / \mathrm{dl}$ \\
Plaquetas & $2,62 \times 10^{5} / \mathrm{mm}^{3}$ \\
Leucócitos totais & $6,14 \times 10^{3} / \mathrm{mm}^{3}$ \\
Linfócitos & $6 \%-369 / \mathrm{mm}^{3}$ \\
Monócitos & $1 \%-62 / \mathrm{mm}^{3}$ \\
Eosinófilos & $0 \%-0 / \mathrm{mm}^{3}$ \\
Neutrófilos segmentados & $88 \%-5404 / \mathrm{mm}^{3}$ \\
Neutrófilos bastonados & $5 \%-307 / \mathrm{mm}^{3}$ \\
\hline
\end{tabular}

Tabela 2. Valores da bioquímica sérica da cadela Pinscher intoxicada por enrofloxacina, após 24 horas de tratamento

\begin{tabular}{lc}
\hline Variável & Valor \\
\hline Uréia & $65 \mathrm{mg} / \mathrm{dl}$ \\
Creatinina & $1 \mathrm{mg} / \mathrm{dl}$ \\
ALT & $197 \mathrm{UI} / 1$ \\
\hline
\end{tabular}

Após 72 horas de tratamento, o animal morreu e foi encaminhado para necropsia, mediante autorização do proprietário. A necropsia e o exame histológico evidenciaram nefrose difusa moderada a severa, vacuolização difusa moderada dos hepatócitos e hemorragia multifocal do fígado, congestão multifocal moderada dos pulmões, congestão difusa severa e necrose focal extensiva moderada do pâncreas, congestão difusa moderada do estômago e choque hipovolêmico.

\footnotetext{
${ }^{12}$ Multistix - Bayer S.A Diagnóstica - São Paulo - Brasil.
} 
Tabela 3. Urinálise da cadela Pinscher intoxicada por enrofloxacina, após 24 horas de tratamento

\begin{tabular}{lc}
\hline Variável & Resultado \\
\hline Exame físico-químico & Límpido \\
Aspecto & Amarelo-claro \\
Cor & 6,5 \\
$\mathrm{pH}$ & 1.010 \\
Densidade & $3+(\geq 2000 \mathrm{mg} / \mathrm{dl})$ \\
Glicose & Negativo \\
Bilirrubina & Negativo \\
Cetona & $2+$ \\
Sangue & Negativo \\
Proteínas & Normal \\
Urobilinogênio & Negativo \\
Nitrito & Negativo \\
Leucócitos & \\
Exame do sedimento & $6 /$ campo \\
Leucócitos & $539 /$ campo \\
Eritrócitos & Negativo \\
Bacteriúria & $177 /$ campo \\
Células epiteliais & $4 /$ campo \\
Cilindros leucocitários & $2 /$ campo \\
Cilindros epiteliais & Oxalato de cálcio (1/campo $)$ \\
Cristais &
\end{tabular}

\section{DISCUSSÃO}

A literatura veterinária consultada relata que nas intoxicações por enrofloxacina em animais, o tratamento indicado é a indução do vômito ou lavagem gástrica, observação clínica e terapia suporte, no que se inclui hidratação e diálise (USP..., 2003). No caso relatado, foi utilizado fluidoterapia, oxigenioterapia e tratamento medicamentoso para gastrite, anúria convulsão e parada respiratória. Não foi realizada lavagem gástrica, visto que a enrofloxacina foi administrada de forma injetável, sendo necessário aguardar a metabolização hepática da droga e sua excreção biliar e renal (Otero et al., 2001).

Plumb (1999) afirmou que é improvável a ocorrência de sintomas mais sérios do que anorexia e vômito, na administração de 10 vezes a dosagem recomendada de enrofloxacina. O óbito é observado quando se utiliza dose 25 vezes maior do que a recomendada, durante 11 dias. Entretanto, o presente relato mostra que na dose 10 vezes superior a recomendada, por apenas dois dias, ocorreram além de gastrite, lesões severas nos rins, fígado, pâncreas e sistema nervoso central, resultando em óbito. Os achados de necropsia evidenciaram que os tecidos alvos da droga na cadela foram o trato urinário, trato digestivo e o sistema nervoso central, conforme preconizam Vancutsem et al (1990) e Sárközy (2001) e medula óssea (USP..., 2003).

Suspeita-se que a alta concentração alcançada na urina pela enrofloxacina e sua baixa solubilidade em $\mathrm{pH}$ ácido, afirmado por Vancutsem et al. (1990), resultou em cristalúria e nefrite intersticial. De acordo com Vancutsem et al. (1990) e Otero e al. (2001), os cristais formados seriam os responsáveis pelas lesões renais observadas. Entretanto, segundo Patterson (1991) e Dietz (1997), no homem a cristalúria é mais comum em urina alcalina, ao contrário dos dados obtidos no presente relato, no qual houve formação de cristais em urina ácida.

A presença de cilindros leucocitários e epiteliais caracterizaram a nefrite intersticial (Tab. 3), que pôde ser confirmada pelo exame histopatológico. Provavelmente, a nefrite foi provocada pela ação do metabólito ciprofloxacina nos túbulos renais, visto que a nefropatia é mais relatada pelo uso da ciprofloxacina (Dietz, 1997). A baixa densidade urinária observada na urinálise (Tab. 3), pode ter ocorrido conseqüente à fluidoterapia realizada nas primeiras 24 horas.

A anemia macrocítica hipocrômica, observada no hemograma (Tab. 1), pode ter se originado em resposta à elevada concentração da enrofloxacina na medula óssea, uma vez que este é um dos locais da distribuição deste fármaco, conforme o USP (2003). Além disso, observou-se a hematúria na urinálise (Tab. 3), o que justificaria a acentuada anemia, decorrente da ação do metabólito ciprofloxacina nos túbulos renais (Dietz, 1997). Também foi constatado no hemograma, neutrofilia e eosinopenia (Tab. 1), diferindo dos achados de Ellenhorn (1997), que observou neutropenia e eosinofilia em humanos.

A congestão e necrose do pâncreas, associadas a glicosúria observada na urinálise, sugerem que o animal tenha desenvolvido diabete melito aguda ou pancreatite, porém não referidas na literatura consultada. 
A necrose e a hemorragia hepática multifocal, associada ao aumento da ALT sérica (Tab. 2) pode ser explicada pela alta concentração que a enrofloxacina e seu metabólito ciprofloxacina atingiram nos hepatócitos. Admite-se que o mesmo mecanismo tenha ocorrido no epitélio bronquial, resultando em necrose multifocal moderada dos pulmões, observada na necropsia (Otero et.al., 1990; Hawkins et al., 1998).

Concentrações séricas elevadas de norfloxacina endovenosa produzem reações tóxicas imediatas no SNC, possivelmente devido a grande liberação de histamina. Consistem em convulsão, defecação, micção e emese dentro de dois a três minutos após injeção rápida desse fármaco (Sárközy, 2001). No caso relatado, a enrofloxacina foi administrada por via subcutânea e os episódios de vômito se iniciaram após três horas da administração.

A intoxicação do SNC em humanos é relatada por Dietz (1997) como um dos efeitos colaterais mais urgentes nos casos de dose excessiva de fluorquinolonas. Essas drogas diminuem o limiar de convulsão e impedem a transmissão neuromuscular (Cohen, 2001), desencadeando o quadro convulsivo. Pelo fato das fluorquinolonas competirem por receptores GABA, os benzodiazepínicos constituem o tratamento apropriado (Dietz, 1997; Cohen, 2001), o motivo pelo qual o diazepam foi eficiente no controle das convulsões na cadela do presente relato.

Apesar da interação da enrofloxacina com os antiinflamatórios não-esteróides (AINES) desencadear convulsões pela inibição excessiva do GABA, o significado para outros agentes é questionável, visto que não foram relatados casos com outras combinações de fluorquinolonas e AINES (Dietz, 1997). No presente relato, foi utilizado cetoprofeno durante dois dias, concomitante ao uso de enrofloxacina, e nenhuma reação adversa foi observada durante tal tratamento. As convulsões surgiram após dois dias do uso da enrofloxacina.

Admite-se que o choque hipovolêmico ocorrido no terceiro dia após o início da terapia contra a intoxicação por enrofloxacina foi a causa mortis da cadela. Provavelmente, o choque ocorreu devido às alterações sistêmicas provocadas pela enrofloxacina e seus metabólitos nos tecidos alvo, conforme citado por Vancutsem et al (1990).

\section{CONCLUSÃO}

A intoxicação por enrofloxacina em cão pode ocorrer com apenas dois dias da administração na dose de $50 \mathrm{mg} / \mathrm{kg}$, provocando gastrite, lesões renais, hepáticas, pancreáticas e no sistema nervoso central, além de choque hipovolêmico.

\section{REFERÊNCIAS BIBLIOGRÁFICAS}

COHEN, J.S. Peripheral neuropathy associated with fluorquinolones. Annals Pharmacoth., v.35, p1-7, 2001.

DIETZ, B.L. The fluoroquinolones. Clinical Toxicology Review, v.20, n.3. Disponível em: www. maripoisoncenter.com/ctr/9712Fluoroquinolones.html. Acesso em: 18.jun.2003

ELLENHORN, M.J. Ellenhorn's medical toxicology diagnosis and treatment of human poisoning. 2.ed. Pennsylvania: Williams \& Wilkins, 1997. Section II, part B: Anti-infective drugs: p.224-304.

HAWKINS, E.C.; BOOTHE, D.M.; GUINN, A. et al. Concentration of enrofloxacin and its active metabolite in alveolar macrophages and pulmonary epithelial lining fluid of dog. J. Vet. Pharmacol. Therap., v.21, p.18-23, 1998.

KÜNG, K.; RIOND, J.L.; WANNER, M. Pharmacokinetics of enrofloxacina and its metabolite ciprofloxacina after intravenous and oral administration of enrofloxacina in dogs. J. Vet. Pharmacol. Therap., v.16, p.462-468, 1993.

OTERO, J.L.; MESTORINO, N.; ERRECALDE, J.O. Enrofloxacina: una fluorquinolona de uso exclusivo en veterinaria. Parte II: farmacocinetica y tocicidad. Anal. Vet., v.21, p.42-49, 2001.

PATTERSON, D.R. Quinolone toxicity: methods of assessment. Am. J. Med., v.91, p.35 S- 37 S, 1991.

PLUMB, D.C. Veterinary drug handbook. 3.ed. Pocket edition. Iowa: Iowa State University, 1999. 853p.

SÁRKÖZY, G. Quinolones: a class of antimicrobial agents. Vet. Med-Czech., v.46, p.257-274, 2001.

USP VETERINARY DRUG INFORMATION. The United States Pharmacopeial Convention. Disponível em: $<$ http://www.usp.org/pdf/veterinary/enrofloxacin.pdf $>$ Acesso em: 18 jun. 2003.

VANCUTSEM, P.M.; BABISH, J.G.; SCHWARK, W.S. The fluorquinolone antimicrobials: structure, antimicrobial activity, pharmacokinetics, clinical use in domestic animals and toxicity. Cornell Vet., v.80, p.173186, 1990. 